\title{
Immature control of breathing and apnea of prematurity: the known and unknown
}

\author{
Grant Erickson ${ }^{1} \cdot$ Nicole R. Dobson $\mathbb{(}^{2}{ }^{2}$ Carl E. Hunt ${ }^{2}$
}

Received: 30 October 2020 / Revised: 5 February 2021 / Accepted: 16 February 2021 / Published online: 12 March 2021

This is a U.S. government work and not under copyright protection in the U.S.; foreign copyright protection may apply 2021

\begin{abstract}
This narrative review provides a broad perspective on immature control of breathing, which is universal in infants born premature. The degree of immaturity and severity of clinical symptoms are inversely correlated with gestational age. This immaturity presents as prolonged apneas with associated bradycardia or desaturation, or brief respiratory pauses, periodic breathing, and intermittent hypoxia. These manifestations are encompassed within the clinical diagnosis of apnea of prematurity, but there is no consensus on minimum criteria required for diagnosis. Common treatment strategies include caffeine and noninvasive respiratory support, but other therapies have also been advocated with varying effectiveness. There is considerable variability in when and how to initiate and discontinue treatment. There are significant knowledge gaps regarding effective strategies to quantify the severity of clinical manifestations of immature breathing, which prevent us from better understanding the long-term potential adverse outcomes, including neurodevelopment and sudden unexpected infant death.
\end{abstract}

\section{Introduction}

Apnea-related symptoms are the clinical manifestation of immature control of breathing and are a common occurrence in the neonatal intensive care unit (NICU) [1-5]. The clinical diagnosis of apnea of prematurity (AOP) relies on evidence of prolonged apnea lasting 15-20s or more, or shorter durations if associated with bradycardia or desaturation. Virtually all infants $<28$ weeks gestation have AOP-related symptoms, decreasing to only about $20 \%$ at 34 weeks and $<10 \%$ beyond 34 weeks gestation $[6,7]$.

In this narrative review, we will address (1) the pathophysiology of immature control of breathing and its clinical manifestations; (2) pharmacological and nonpharmacological therapies for AOP; (3) resolution of clinical symptoms of AOP and readiness for discharge home; (4) post-discharge outcomes, including neurodevelopmental sequelae, brief

Nicole R. Dobson

nicole.dobson@usuhs.edu

1 National Capital Consortium Neonatal-Perinatal Medicine Fellowship, Uniformed Services University, Bethesda, MD, USA

2 Department of Pediatrics, Uniformed Services University, Bethesda, MD, USA resolved unexplained events (BRUE), sudden infant death syndrome (SIDS), and sleep disordered breathing (SDB); and (5) gaps in knowledge with future research directions. The methodology for this narrative review was based on a comprehensive summary of known studies published in English and supplemented by a PubMed search for additional relevant publications. Both sources were supplemented by a review of all relevant secondary references. Publications only as abstracts were not included.

\section{Pathophsyiology}

Control of breathing is a complex process with neurons in the respiratory control centers of the bulbopontine region of the brainstem responsible for rhythmogenesis. Neurons within this region respond to multiple afferent inputs to modulate rhythmicity and provide efferent output to respiratory control muscles. The afferent inputs include signals from peripheral and central chemoreceptors, pulmonary stretch receptors, and cortical neurons. Preterm infants exhibit immature control of breathing, which includes aberrant activity of both central and peripheral chemoreceptors as well as poor neuromuscular control of upper airway patency (Fig. 1) [2]. Due to immaturity, central chemosensitivity to hypercarbia is diminished in 
Fig. 1 The pathophysiology of apnea of prematurity.

Brainstem respiratory centers demonstrate both immature central and peripheral chemoreceptor responses and diminished neuromuscular control of upper airway patency. In addition to prolonged apneas leading to bradycardia and desaturation, the immature respiratory centers also result in shorter respiratory pauses and periodic breathing. Peripheral chemoreceptors mature more rapidly postnatally than central chemoreceptors, which can result in the cyclic pattern of periodic breathing and intermittent hypoxia.

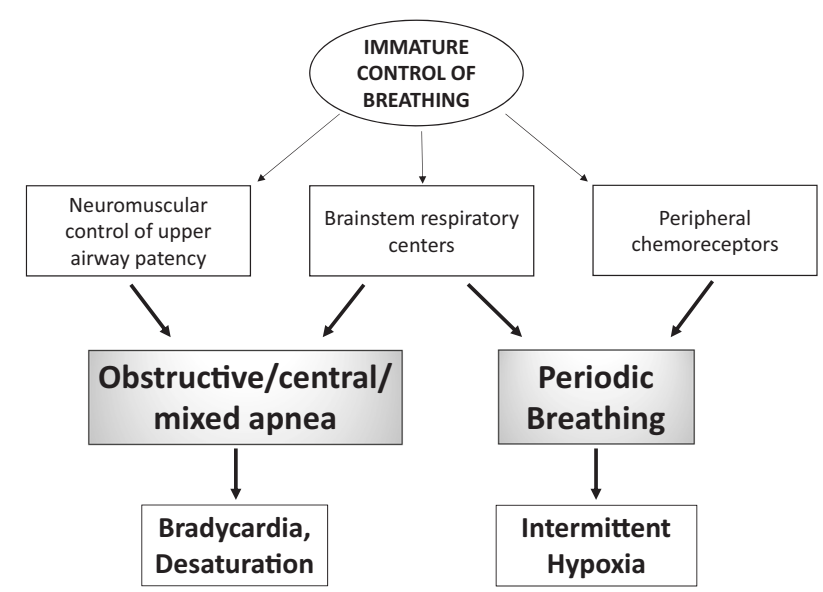

infants born preterm, and when matched for gestational age, further reduced with AOP-related symptoms. Chemosensitivity to hypoxia is also impaired and is characterized by a biphasic response. The initial response is hyperventilatory and likely due to peripheral chemoreceptor input, but this initial hyperventilation may not occur in extremely preterm infants. The secondary depressive ventilatory response to hypoxia is due primarily to centrally mediated suppression of peripheral chemoreceptor activity $[2,8]$.

Apnea is the best known symptomatic indicator of immature control of breathing, and bradycardia or desaturations are common consequences of prolonged apneas. Apnea can be central, obstructive, or mixed (Fig. 1) [8]. Mixed apneas can begin either with obstructive breaths or central apnea. Obstructive apneas are related to absent neuromuscular upper airway control, but all three apnea types are related to brainstem immaturity [3]. Mixed apneas with loss of upper airway patency at the end of a central pause are the most common type in the NICU, and mixed or obstructive events account for the majority of apneas [9]. It is unknown if the frequency of mixed apneas differ in preterm infants born at lower gestational ages than those included in published studies. Most studies of apnea type and mixed apnea preponderance have been limited to the acute phase of immature breathing in the NICU, but the Collaborative Home Infant Monitoring Evaluation (CHIME) Study included outpatient recordings in infants born $\leq 34$ weeks gestation from term-equivalent age through 4-6 months postnatal age; using respiratory inductance plethysmography to assess apnea type, these recordings confirmed that most long apneas continued to be mixed, with about $70 \%$ of all apneas including at least three obstructed breaths $[10,11]$.

Additional clinical manifestations of immature control of breathing include shorter respiratory pauses that can be isolated or occur in clusters [12, 13]. Respiratory pauses occurring in clusters manifest as periodic breathing, which is an oscillatory breathing pattern due to hyperventilation followed by brief apneas or respiratory pauses [14-16]. Periodic breathing is primarily a consequence of immature brainstem control, but peripheral chemoreceptors are also of critical importance (Fig. 1) [9, 17]. Indeed, periodic breathing appears to be related at least in part to increased sensitivity or gain in peripheral chemoreceptors leading to overcompensation for small changes in $\mathrm{PaO}_{2}$ or $\mathrm{PaCO}_{2}$ and hence oscillations between brief episodes of tachypnea leading to relative hypocarbia that results in apnea in a cyclic pattern [15].

The prevalence of periodic breathing may approach $100 \%$ at very low gestational ages, and progressively decreases with increasing postnatal and postmenstrual age (PMA), reaching a nadir by about 44 weeks PMA $[15,18]$. The respiratory pauses in periodic breathing are generally not of sufficient duration to cause bradycardia or desaturation that trigger monitor alarms or to be evident clinically unless occurring in prolonged clusters. Intermittent hypoxia (IH) is perhaps the most important consequence of periodic breathing, but requires continuous respiratory recording for documentation. In preterm infants $<28$ weeks gestation, IH frequency is lowest in the first postnatal week, progressively 
increases over the first 4 weeks, and then progressively decreases after 6-8 weeks postnatal age [19]. This time course coincides with a more rapid maturation in peripheral relative to central chemoreceptors and hence greater cyclic instability. This time course may also be affected in part by sleep state maturation; periodic breathing and hence IH occur primarily during quiet (NREM) sleep, which is at a nadir initially but progressively increases with increasing postnatal age $[9,15,16,20]$.

The AOP phenotype has been attributed solely to immature control of breathing consequent to preterm birth but there may also be important genetic influences. In one study of heritability of AOP, twin modeling demonstrated that the heritability of AOP is $87 \%$ (95\% CI $0.64-0.97$ ) among same-gender twins; genetic factors accounted for 99\% (95\% CI 0.89-1.00) of the variance in AOP in males, but only $78 \%$ (95\% CI $0.49-0.94$ ) in females [21], but shared environment was not a significant influence. As an additional effect of genotype, polymorphisms in the adenosine $A_{1}$ and $A_{2 A}$ receptor genes have been associated with a higher risk of $\mathrm{AOP}$ and increased variability in response to methylxanthine therapy [22, 23].

In summary, AOP and periodic breathing with $\mathrm{IH}$ are manifestations of immature control of breathing due to central and peripheral chemoreceptor immaturity. The severity of immature control of breathing and its clinical manifestations are inversely associated with gestational age at birth. Clusters of periodic breathing and associated IH may be as important as prolonged apneas in determining risk for long-term morbidities. The extent to which genotype affects the phenotype of AOP is unknown, but an important focus for future research.

\section{Therapeutic strategies}

There is no consensus on when to initiate therapy for AOP. Generally, treatment is indicated when episodes are recurrent, do not resolve spontaneously or with minimal stimulation, and are associated with bradycardia or hypoxemia. Various nonpharmacological therapies have been advocated for AOP, but the first line of therapy is usually a methylxanthine, specifically caffeine.

\section{Methylxanthines}

Methylxanthines have been used for $>40$ years to treat AOP. Early studies using aminophylline and theophylline showed they effectively reduced the incidence of apnea [24]. Caffeine, a trimethylxanthine, is the major metabolite of the dimethylxanthine theophylline and demonstrates more potent central activity and less peripheral effects. Caffeine has become the preferred methylxanthine due to fewer side effects, a wider therapeutic index, and a longer half-life that allows once-daily dosing [25, 26].

Methylxanthines act both centrally and peripherally to stimulate respiration through antagonism of adenosine $A_{1}$ and $\mathrm{A}_{2 \mathrm{~A}}$ receptors They activate the medullary respiratory centers and increase $\mathrm{CO}_{2}$ sensitivity, induce bronchodilation, and enhance diaphragmatic function, all of which lead to increased minute ventilation, improved respiratory pattern, and reduced hypoxic respiratory depression [24]. Studies suggest that the primary mechanism by which methylxanthines reduce apnea is antagonism of excitatory $\mathrm{A}_{2 \mathrm{~A}}$ receptors on GABAergic neurons and blockade of inhibitory $A_{1}$ receptors, with resultant stimulation of central respiratory neural output $[27,28]$.

Caffeine is metabolized in the liver by the cytochrome P450 enzyme system. The enzymes responsible for its metabolism are functionally deficient at birth, but mature progressively with increasing gestational age and postnatal age. In the early postnatal weeks, elimination of caffeine mainly occurs by renal excretion in preterm infants. The clearance of caffeine is very slow and the plasma half-life very prolonged in preterm infants, ranging from 41 to $231 \mathrm{~h}$ $[29,30]$. Oral caffeine is completely absorbed, facilitating the transition from intravenous to oral preparations when infants are able to tolerate enteral medications.

\section{Caffeine dosing}

The initial studies of caffeine citrate for AOP that led to FDA approval used a loading dose of $20 \mathrm{mg} / \mathrm{kg}$ followed by a daily maintenance dose of $5 \mathrm{mg} / \mathrm{kg}$ in infants born between 28 and 33 weeks' gestation. This dosing regimen generated concentrations within the recommended therapeutic range of $5-25 \mu \mathrm{g} / \mathrm{mL}$. A recent study from the Pediatric Trials Network confirmed the safety of maintenance doses up to 10 $\mathrm{mg} / \mathrm{kg} /$ day in extremely preterm infants for longer durations than recommended on the drug label [31]. Other studies have suggested that higher dose regimens convey therapeutic advantages without increasing adverse effects. Compared to standard dosing regimens, higher dosing regimens (loading doses up to $80 \mathrm{mg} / \mathrm{kg}$, maintenance doses of $10-20 \mathrm{mg} / \mathrm{kg} / \mathrm{day}$ ) have been shown to be more effective in reducing apnea and preventing extubation failure [32]. A recent retrospective study associated a higher average daily dose of caffeine with improved neurodevelopmental outcomes [33]. However, some concerns about adverse effects have limited the use of high-dose caffeine. One study showed a higher incidence of cerebellar hemorrhage with early high-dose caffeine compared to standard dosing, but there was no difference in developmental outcomes at 2 years [34]. Well-designed randomized controlled trials are needed to determine the optimal dose of caffeine to treat AOP and to optimize neonatal outcomes. 


\section{Side effects/toxicity of methylxanthine therapy}

Adenosine receptors are present throughout the brain as well as in the heart, blood vessels, respiratory system, gastrointestinal system, and kidneys. Since methylxanthines are nonspecific adenosine antagonists, their use can lead to secondary effects in organ systems outside the brain. The side effects of methylxanthine therapy result from increased metabolic rate and catecholamine stimulation, leading potentially to transient tachycardia, irritability, and slowing of growth. In the Caffeine for Apnea of Prematurity (CAP) trial, caffeine-treated infants gained less weight during the first 3 weeks after randomization but by 4 weeks there was no difference in weight gain, and there were no long-term adverse effects on growth [35-37]. Animal studies and small clinical trials show that caffeine delays gastric emptying time, decreases lower esophageal sphincter tone, and transiently reduces splanchnic oxygenation but the clinical significance of these findings is uncertain [38-40]. Importantly, the CAP trial observed no differences in the rate of NEC between caffeine and placebo groups [35].

In preterm infants studied $>12 \mathrm{~h}$ after starting caffeine, urine flow and urinary sodium excretion increased [41], potentially impacting fluid management. However, these effects on renal function appear to be beneficial. In the Assessment of Worldwide Acute Kidney Injury Epidemiology in Neonates study, preterm infants treated with caffeine in the first week of life had a decreased incidence and severity of acute kidney injury [42].

Case reports of caffeine toxicity in preterm infants have described a variety of symptoms, including seizures, cardiac arrhythmias, and rhabdomyolysis [24, 43, 44]. Signs of toxicity are generally not seen until levels exceed $40 \mu \mathrm{g} / \mathrm{mL}$. Therefore, measuring drug concentrations is not recommended in the absence of persistent apnea-related symptoms or potential toxicity [24, 45].

\section{Clinical use}

In addition to reducing apnea-related symptoms, methylxanthines facilitate extubation and reduce the need for mechanical ventilation [46]. The CAP trial revealed many other benefits of caffeine therapy for extremely preterm infants born $<1250 \mathrm{~g}$, including reductions in the incidence of bronchopulmonary dysplasia (BPD), need for patent ductus arteriosus (PDA) treatment, severity of retinopathy of prematurity (ROP), and improved long-term neurodevelopment related to motor function [36, 37]. In a subset followed to 11 years, children treated with caffeine had improved lung function [47].

In the CAP Trial, the benefits of caffeine were most significant when treatment was initiated within 3 days after birth [48]. Several retrospective cohort studies have associated earlier initiation of caffeine therapy with improved outcomes, but the evidence is generally of low quality and has to be interpreted with caution [24, 49]. The only randomized, controlled trial investigating early caffeine administration in extremely preterm ventilated infants was terminated early due to concern for higher mortality in the early caffeine group without any clinical benefit; however, baseline demographic differences between the groups and small sample size limit the ability to draw definitive conclusions [50]. Nevertheless, clinical practice has evolved and early initiation of caffeine treatment has become very common in extremely preterm infants, with $62 \%$ of international neonatologists reporting prophylactic use [51].

The optimal duration of treatment with a methylxanthine is highly variable. Neonatologists typically use a combination of PMA, length of time since the last documented clinical episode, and general clinical status to decide when to stop treatment. After stopping, most physicians will observe an infant for 3-8 days during drug "washout" before concluding that the infant is ready for discharge [52]. Recent data suggest that infants continue to have concentrations of caffeine $\geq 5 \mu \mathrm{g} / \mathrm{mL}$ for 5-10 days after drug discontinuation, especially when the maintenance dose at discontinuation is greater than $5 \mathrm{mg} / \mathrm{kg} /$ day [53, 54]. Infants developing recurrent clinical symptoms of bradycardia or desaturation after stopping caffeine may require reinstitution of treatment.

\section{Noninvasive respiratory support strategies}

Nasal continuous positive pressure (CPAP) is effective in treating apnea by splinting open the upper airway to improve patency and through improved oxygenation by increasing functional residual capacity [55]. Heated humidified high flow nasal cannula (HHFNC) use has become increasing popular and is often used interchangeably with CPAP for treatment. Small studies have demonstrated comparable positive distending pressures between HHFNC and CPAP with no differences in rate of AOP-related symptoms [56, 57]. HHFNC thus appears to be an acceptable alternative to CPAP in treatment of AOP, but larger studies are needed to delineate any differences in frequency and severity of AOP-related symptoms between these modalities.

Nasal intermittent positive pressure ventilation (NIPPV) may be more effective than CPAP in reducing AOP-related symptoms, but earlier studies of non-synchronized NIPPV showed mixed results [58, 59]. A randomized crossover study comparing synchronized NIPPV (sNIPPV) to standard therapies demonstrated a reduction in central apneas with sNIPPV [60], but this study was limited by small sample size and a short study period. A recent retrospective study of NIPPV triggered via neurally adjusted ventilatory 
assistance (niNAVA) showed a reduction in bradycardic events and more periods without events while on niNAVA compared to NIPPV, though there was no difference in the number of apnea events [61]. Another retrospective study showed a reduction in clinically significant events with niNAVA compared to CPAP [62]. These synchronized modalities show promise for improvement in management of AOP but further studies are needed to confirm the benefit.

\section{Gastric acid suppression}

The association of AOP with gastroesophageal reflux (GER) has been very controversial. Researchers continue to examine if a causal relationship between these entities can be established. A review summarizing the most recent studies reiterated that there is not sufficient evidence to support a temporal, much less a causal, relationship between GER and AOP [63]. Combined with data suggesting harmful effects, gastric acid suppression is not indicated for the treatment of AOP.

\section{Blood transfusions}

Anemia may exacerbate apnea by reducing oxygen-carrying capacity of the blood and decreasing oxygen delivery to the brain. Previous studies have provided conflicting evidence for the effectiveness of blood transfusions to reduce apnea episodes due to study design limitations, including lack of blinding and retrospective identification of events based on chart review. Utilizing continuous waveform analysis, a retrospective study demonstrated that blood transfusions decreased apnea events on a short-term basis and that a lower hematocrit was associated with increased frequency of apnea [64]. This study, however, could not account for many variables that contribute to AOP-related symptoms or for the initial indication for blood transfusion. Another recent study demonstrated an improvement in $\mathrm{IH}$ following transfusion after the first week of life [65]. While this study did not include any direct recording of apneic events, it did demonstrate that the timing of packed red blood cell (PRBC) transfusion may have important implications for its effectiveness in management of AOP-related symptoms. A decreased frequency of $\mathrm{IH}$ was observed after PRBC transfusions but not non-PRBC transfusions, suggesting that the observed beneficial effects of blood transfusions on apnea are mediated through an enhanced oxygen-carrying capacity [66]. Despite these additional studies, there are still no data showing long-term reduction in apnea events following transfusions. Additional investigation of neurodevelopmental outcomes following liberal versus restrictive transfusion thresholds are needed to determine optimal management strategies for treatment of AOP [67].

\section{Other therapies}

A variety of other pharmacologic and non-pharmacologic treatments have been proposed in the management of AOP (Tables 1, 2). These strategies have not been widely employed either because of concerning side effects, limited cost-effectiveness, or non-superiority compared to established therapies. Some of these treatments have shown potential in animal models, but definitive translational studies have not yet been conducted.

In summary, the mainstay of treatment for AOP is caffeine, which has substantial benefits for preterm infants born $<1250 \mathrm{~g}$ and minimal adverse effects. Effective nonpharmacologic therapies include noninvasive respiratory support that maintain upper airway patency and functional residual capacity. Blood transfusions may temporarily decrease the frequency of apnea and IH but longer-term benefits have not been confirmed. Other therapies for AOP have unclear efficacy and are not used for routine clinical care.

\section{Resolution of AOP and discharge home}

AOP-related symptoms improve as control of breathing matures with increasing postnatal age and PMA. Clinical resolution generally occurs by 34-36 weeks PMA, but there is considerable individual variation. In infants born at very low gestational ages, apnea-related symptoms may persist to 43-44 weeks PMA and may delay hospital discharge [68]. These infants, however, rarely display apnea lasting longer than $20 \mathrm{~s}$; instead, they exhibit shorter respiratory pauses, IH, and possible bradycardia [68-70].

Many studies have attempted to establish the minimum number of symptom-free hospital days required to ensure that AOP-related symptoms will not recur after discharge home. In the CHIME study, infants with a history of AOP who exhibited apnea-related symptoms within the last 5 days prior to NICU discharge had a higher relative risk of at least one extreme event at home compared to those who had no clinically apparent apnea-related events for $\geq 5$ days before discharge [10]. In a retrospective cohort study of 1400 preterm infants, a 5-7 day apnea-free period predicted resolution of apnea in $\sim 95 \%$ of cases, but the success rate was lower for infants born at $<28$ weeks' gestation [4]. These studies support requiring some days free of AOPrelated events before discharge, but clinical practice remains highly variable. The specified event-free period probably does not need to be uniform for all infants, however, and shorter durations may be considered for infants born at later gestational ages [52].

Providers usually rely on nursing observation and bedside monitors for discharge planning but these often do not 


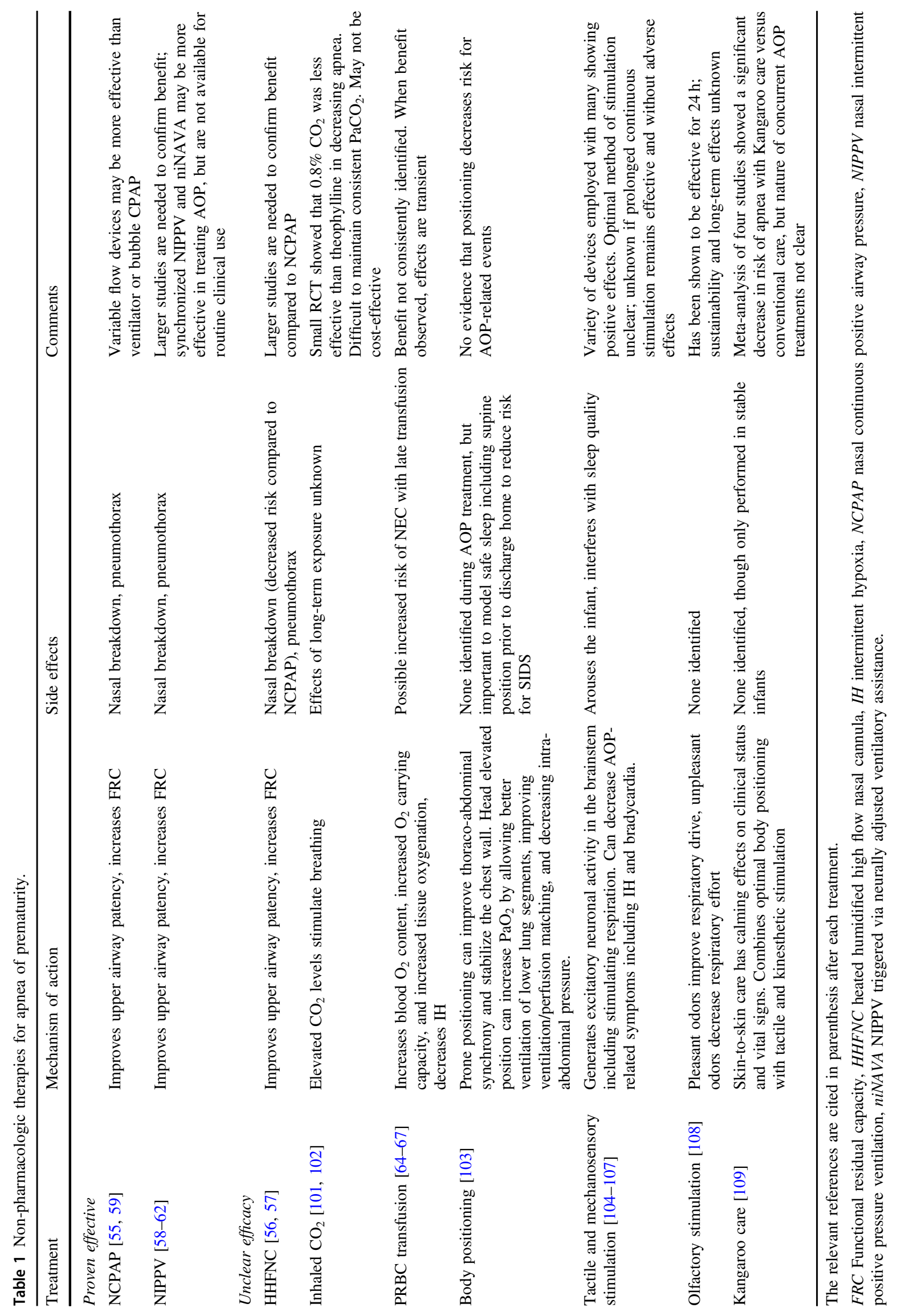


correlate with events recorded electronically [71]. No studies have been done to determine whether the relative risk of having a BRUE or sudden unexpected infant death (SUID) is any greater in infants with shorter symptom-free periods or in whom the event-free period is determined only by clinical observation versus overnight cardiorespiratory recordings. The "Choosing Wisely" campaign recommends that clinicians do not utilize routine cardiorespiratory recordings for determining when to safely discharge infants [72].

There is no consensus on management of infants with persistent AOP-related events who are otherwise ready for discharge. Indications for prescription of home apnea monitors vary by institution and individual providers. Descriptive studies report that home apnea monitors did not result in earlier discharge $[68,73]$. Commercially available wireless pulse oximeters are now available to families for home use without a prescription and are marketed with an emphasis on prevention of SIDS. However, there is no evidence that home monitoring prevents SIDS [74]. Importantly, there also are no studies on effectiveness, benefits, or harms of these wireless oximeters to prevent potential life-threatening events, in infants born full term nor in infants born preterm with prior AOP.

In summary, the symptoms of immature control of breathing progressively improve with increasing age, with resolution around 34-36 weeks PMA. Infants born at younger gestations, however, may have persisting symptoms to 40-44 weeks PMA. Infants need to be symptomfree for a period of time prior to discharge but the optimal duration of observation prior to discharge has not yet been established, and there is no data to support use of home electronic surveillance.

\section{Adverse consequences of immature control of breathing}

The extent to which immature control of breathing and AOP-related symptoms contribute to adverse outcomes is poorly understood. IH is one of the most important consequences of immature breathing patterns. IH in the first month of life in premature infants has been associated with ROP, BPD, and airway hyperreactivity [19, 75-77]. The direct adverse effects of IH on neurodevelopment have not been studied as a consequence of immature control of breathing and AOP. However, studies in animals, and in children and adults with SDB, have confirmed that $\mathrm{IH}$ is pro-inflammatory and associated with cognitive impairments and adverse brain MRI changes [78-81]. A post-hoc analysis of the Canadian Oxygen Trial showed that prolonged IH episodes were associated with adverse neurodevelopmental outcomes at 18 month of age [79]. 
There is a direct correlation between lower gestational age at birth and adverse neurodevelopmental outcomes. Studies have demonstrated neurodevelopmental impairment with increasing number of days of apnea, delayed resolution of apnea, and with both increasing frequency and severity of cardiorespiratory events [82-84]. However, these studies are significantly limited by imprecision in characterizing the frequency and severity of AOP-related symptoms and extent of $\mathrm{IH}$, and absence of data beyond 3 years of age.

In summary, prolonged apneas with significant bradycardia or desaturation including IH appear to increase the risk for adverse outcomes. However, the extent of this increased risk is ill-defined, in large part due to a lack of accurate assessments of the severity of AOP-related symptoms. The impact of IH on adverse neurodevelopment may be at least as important as the risks associated with prolonged and symptomatic apnea, but IH is only clinically evident with continuous recordings with high resolution pulse oximetry, which is not done as a part of routine clinical care.

\section{BRUE, SIDS, and SDB}

Infants born preterm are at increased risk for BRUE, previously defined as apparent life-threatening events [85]. In addition, infants born preterm are at risk for more severe events and for subsequent adverse events after the first event. In a recent report, $90 \%$ of BRUE met the criteria for higher risk, and prematurity was the only risk factor that significantly increased the odds of a recurrent event [86].

Compared to infants born full term, infants born preterm are also at increased risk for SIDS, a subset of SUID [87]. The odds ratio for SIDS progressively increases as the gestational age decreases from full term to 24-28 weeks gestation [88]. The explanation for increased risk in infants born preterm is likely multifactorial, and linked to autonomic consequences of preterm birth interacting with other epidemiological and genetic risk factors including unsafe sleep environments and prone positioning for sleep [89].

Finally, infants born preterm are at increased risk for SDB, with an odds ratio of 1.74 (CI 1.30-2.32; $p<0.001$ ) compared to children born full term [90]. In populationbased cohort studies, the risk for SDB in children born preterm was 3-6 times greater than in term-born children, and $9.6 \%$ of preterm infants born at 500-1250 $\mathrm{g}$ had SDB at school age compared to just $1-2 \%$ in children born full term $[91,92]$. The mechanisms for this increased frequency of SDB in children born preterm have not been established, but abnormalities in orofacial development related to postnatal severity of illness factors have been implicated [93, 94].

In summary, preterm birth is known to increase the risk for BRUE, SIDS, and SDB, with the risk inversely correlated to gestational age at birth. It is unknown, however, to what extent immature control of breathing and severity of AOP-related symptoms including IH may amplify or enhance the relationship of gestational age at birth to these risks [1, 91].

\section{Gaps in knowledge and future directions}

\section{Gaps and limitations}

Despite the frequency of AOP-related symptoms in the NICU, there are still significant gaps in our knowledge that need to be addressed (Table 3 ). One of the main barriers to improved knowledge regarding immature control of breathing is lack of consistent criteria for quantifying the severity of AOP-related symptoms. There is no consensus on severity or duration of associated bradycardia or desaturation, or on the number of events that triggers a diagnosis of AOP. Medical record reviews cannot adequately distinguish between neonates who have few or relatively mild symptoms and those who have frequent or severe manifestations.

Neither bedside nursing observations of AOP-related symptoms nor NICU cardiorespiratory monitors accurately document apnea events [95]. Importantly, clinical electronic monitoring only detects apnea by transthoracic impedance (TTI), which only detects central apnea. Since most AOPrelated apneas are mixed or obstructive, TTI monitors will not detect an event unless associated with bradycardia or desaturation [96]. Apnea detection using respiratory inductance plethysmography, which does accurately detect obstructive apneas, has not been developed for routine clinical use [8$10,97]$. A recently developed apnea detection technology utilized a central network server to collect central apnea (A) events $\geq 10 \mathrm{~s}$ in combination with criteria-based bradycardia (B) and desaturation (D) of any duration incorporated in algorithm-based $\mathrm{ABD}_{10}$ events [12]. This research-based technology is superior to routine clinical methods for detecting symptomatic apnea, but it is a single-site technology, and direct comparisons with recordings that also capture mixed and obstructive apneas have not been reported.

\section{Future directions (Table 3)}

\section{Therapeutic options}

In addition to NIPPV, synchronized NIPPV and neurally adjusted ventilatory assistance (niNAVA) have potential roles in complementing pharmacologic treatment for AOPrelated symptoms. In particular as related to niNAVA, further studies are needed to confirm its cost-effective benefits and to adapt this technology for routine clinical use. 
Table 3 Gaps in knowledge and future research priorities.

\begin{tabular}{|c|c|}
\hline Category & Comments \\
\hline \multicolumn{2}{|l|}{ Gaps in knowledge } \\
\hline Defining AOP-related symptoms & $\begin{array}{l}\text { Lack of consistent criteria and cost-effective strategies for assessing frequency and severity of } \\
\text { AOP-related symptoms in routine clinical care }\end{array}$ \\
\hline Apnea detection $[8,96]$ & $\begin{array}{l}\text { Transthoracic impedance (TTI) is the only technology for apnea detection in routine clinical } \\
\text { practice, but TTI cannot detect obstructive apneas }\end{array}$ \\
\hline \multicolumn{2}{|l|}{ Future research opportunities } \\
\hline sNIPPV and niNAVA [58-61] & $\begin{array}{l}\text { May have advantages over other noninvasive ventilatory strategies, but studies are needed to } \\
\text { confirm cost-effective advantages }\end{array}$ \\
\hline High-dose caffeine [114] & May be beneficial, but needs to be confirmed in large randomized clinical trials \\
\hline When to start and stop caffeine treatment [115] & $\begin{array}{l}\text { Randomized clinical trials are needed to better inform clinicians on optimum time to initiate } \\
\text { treatment, and objective criteria for when to discontinue treatment }\end{array}$ \\
\hline Caffeine vs. new pharmacologic treatments & $\begin{array}{l}\text { Direct prospective comparisons with caffeine of any proposed alternative will be needed to } \\
\text { determine if cost-effective and superior to caffeine }\end{array}$ \\
\hline Apnea detection & $\begin{array}{l}\text { Cost-effective methods for detecting obstructive and mixed apneas or for accurate detection by } \\
\text { indirect methods need to be developed for routine clinical practice }\end{array}$ \\
\hline dEMG [98] & $\begin{array}{l}\text { Diaphragmatic EMG can detect all apnea types and may be a useful clinical strategy, but studies } \\
\text { are needed to determine if cost-effective for routine clinical use }\end{array}$ \\
\hline Intermittent hypoxia $[69,70]$ & $\begin{array}{l}\text { Likely has important impacts on multiple clinical outcomes, but requires continuous high } \\
\text { resolution recordings for detection. Strategies are needed for cost-effective ways to incorporate } \\
\text { in routine clinical practice }\end{array}$ \\
\hline Artificial intelligence [99] & $\begin{array}{l}\text { Currently in the engineering domain, but machine learning strategies may have future role in } \\
\text { predicting significant AOP-related events }\end{array}$ \\
\hline Improved neurodevelopmental outcomes & $\begin{array}{l}\text { New insights from any combination of the above research opportunities may yield improved } \\
\text { recognition and quantification of AOP-related symptoms, and optimize opportunities for } \\
\text { prevention or treatment of clinical symptoms }\end{array}$ \\
\hline
\end{tabular}

The relevant references are cited in parenthesis after each treatment.

$d E M G$ Diaphragmatic electromyography, sNIPPV synchronized nasal intermittent positive pressure ventilation, niNAVA NIPPV triggered via neurally adjusted ventilatory assistance.

Clinical trials are needed to compare the effectiveness of high-dose caffeine regimens to standard-dose regimens, and to better delineate optimal time to initiate caffeine therapy. Head-to-head comparisons of caffeine with other pharmacologic strategies should be done if and when alternative drug therapies are identified, especially in infants with AOP-related symptoms refractory to treatment. Two current ongoing studies investigating extended caffeine therapy (ICAF and MOCHA, NCT03321734, and NCT03340727, respectively) may yield new insights regarding the optimal time to stop therapy. Extended caffeine treatment after discharge home decreases the extent of persisting $\mathrm{IH}$ and has not been associated with any known risks [69]. However, persisting IH is not associated with any acute clinical symptoms, and there is currently no evidence that persisting IH causes any acute injury, is a risk for either a BRUE or for SIDS, or adversely affects later neurodevelopment.

\section{Apnea detection}

Cost-effective technologies for clinical use are needed that can accurately detect mixed and obstructive as well as central apneas. The automated technology described above $\left(\mathrm{ABD}_{10}\right)$ may be a promising alternative, but this technology is not commercially available and currently neither cost-effective nor practical for incorporation into routine clinical practice [12].

An alternative to direct apnea recordings to detect obstructive and mixed apneas is the assessment of electrical activity of the diaphragm using transcutaneous electromyography (dEMG) [98]. This research-based technology improves the accuracy of apnea classification compared to TTI, but is not presently adaptable for cost-effective use in routine clinical care.

A computational framework for assessing apnea based on multimodal measurements followed by machine learning is another promising approach [99]. Although presently still in the engineering domain, such frameworks may represent future translational research opportunities, with cost-effective potential that could improve clinical practice and outcomes.

\section{Intermittent hypoxia}

IH requires continuous recordings for accurate identification and analysis. Studies are needed to determine cost-effective 
strategies for assessing IH in the NICU, track the extent of $\mathrm{IH}$ during and following resolution of acute AOP-related symptoms, determine adverse consequences of $\mathrm{IH}$, and assess potential strategies to ameliorate its sequelae $[69,70]$.

In summary, additional studies are needed to refine optimal strategies for initiating and stopping caffeine treatment, which also should contribute to reducing the extensive variability in management of AOP [100]. In addition to improving methodologies for apnea detection, strategies are needed to detect and quantify $\mathrm{IH}$, arguably the most important downstream consequence of immature control of breathing, and to track IH both acutely and following resolution of treatment for clinically apparent AOPrelated symptoms. Addressing the current limitations in knowledge will require translational studies of emerging technologies to explore cost-effective strategies for use in routine clinical practice. However, addressing these gaps in knowledge offers compelling new directions with high potential to change clinical practice and yield new insights into the mechanistic links for adverse outcomes including neurodevelopmental impairment, and risk for BPD, ROP, BRUE, SIDS, and SDB.

Author contributions All authors were involved in the design of included content, review of the recent literature, development of tables and figures, and the writing of the paper.

\section{Compliance with ethical standards}

Conflict of interest The authors declare no competing interests. The views expressed in this review do not reflect the official policy or position of the United States Air Force, Army, Navy, Department of Defense, or the U.S. Government.

Publisher's note Springer Nature remains neutral with regard to jurisdictional claims in published maps and institutional affiliations.

\section{References}

1. Yiallourou SR, Witcombe NB, Sands SA, Walker AM, Horne RS. The development of autonomic cardiovascular control is altered by preterm birth. Early Hum Dev. 2013;89:145-52.

2. Martin RJ, Wilson CG. Apnea of prematurity. Compr Physiol. 2012;2:2923-31.

3. Poets CF. Apnea of prematurity: what can observational studies tell us about pathophysiology? Sleep Med. 2010;11:701-7.

4. Lorch SA, Srinivasan L, Escobar GJ. Epidemiology of apnea and bradycardia resolution in premature infants. Pediatrics. 2011;128:e366-73.

5. Dobson NR, Thompson MW, Hunt CE. Control of breathing: maturation and associated clinical disorders. In: JP Boardman AG, J Ramasethu, editors. 8th ed. of Avery and MacDonald's Neonatology Pathophysiology and Management of the Newborn: Wolters Kluwer Health; 2021.
6. Henderson-Smart DJ. The effect of gestational age on the incidence and duration of recurrent apnoea in newborn babies. Aust Paediatr J. 1981;17:273-6.

7. Barrington K, Finer N. The natural history of the appearance of apnea of prematurity. Pediatr Res. 1991;29:372-5.

8. Di Fiore JM, Poets CF, Gauda E, Martin RJ, MacFarlane P. Cardiorespiratory events in preterm infants: etiology and monitoring technologies. J Perinatol. 2016;36:165-71.

9. Di Fiore JM, Martin RJ, Gauda EB. Apnea of prematurityperfect storm. Respir Physiol Neurobiol. 2013;189:213-22.

10. Ramanathan R, Corwin MJ, Hunt CE, Lister G, Tinsley LR, Baird $\mathrm{T}$, et al. Cardiorespiratory events recorded on home monitors: Comparison of healthy infants with those at increased risk for SIDS. JAMA. 2001;285:2199-207.

11. Hunt CE, Corwin MJ, Lister G, Weese-Mayer DE, Ward SL, Tinsley LR, et al. Precursors of cardiorespiratory events in infants detected by home memory monitor. Pediatr Pulmonol. 2008;43:87-98.

12. Fairchild K, Mohr M, Paget-Brown A, Tabacaru C, Lake D, Delos J, et al. Clinical associations of immature breathing in preterm infants: part 1-central apnea. Pediatr Res. 2016;80:21-7.

13. Marshall AP, Lim K, Ali SK, Gale TJ, Dargaville PA. Physiological instability after respiratory pauses in preterm infants. Pediatr Pulmonol. 2019;54:1712-21.

14. Al-Matary A, Kutbi I, Qurashi M, Khalil M, Alvaro R, Kwiatkowski $\mathrm{K}$, et al. Increased peripheral chemoreceptor activity may be critical in destabilizing breathing in neonates. Semin Perinatol. 2004;28:264-72.

15. Patel M, Mohr M, Lake D, Delos J, Moorman JR, Sinkin RA, et al. Clinical associations with immature breathing in preterm infants: part 2-periodic breathing. Pediatr Res. 2016;80:28-34.

16. Seppä-Moilanen M, Andersson S, Rantakari K, Mikkola K, Kirjavainen T. Caffeine and supplemental oxygen effectively suppress periodic breathing with only minor effects during long episodes of apnoea in preterm infants. Acta Paediatr. 2019;108:443-51.

17. MacFarlane PM, Ribeiro AP, Martin RJ. Carotid chemoreceptor development and neonatal apnea. Respir Physiol Neurobiol. 2013;185:170-6.

18. Hunt CE, Corwin MJ, Weese-Mayer DE, Ward SL, Ramanathan R, Lister G, et al. Longitudinal assessment of hemoglobin oxygen saturation in preterm and term infants in the first six months of life. J Pediatr. 2011;159:377-83.e1.

19. Di Fiore JM, Bloom JN, Orge F, Schutt A, Schluchter M, Cheruvu VK, et al. A higher incidence of intermittent hypoxemic episodes is associated with severe retinopathy of prematurity. J Pediatr. 2010;157:69-73.

20. Cailleau L, Weber R, Cabon S, Flamant C, Roué J-M, Favrais G, et al. Quiet sleep organization of very preterm infants is correlated with postnatal maturation. Front Pediatr. 2020;8:559658.

21. Bloch-Salisbury E, Hall MH, Sharma P, Boyd T, Bednarek F, Paydarfar D. Heritability of apnea of prematurity: a retrospective twin study. Pediatrics. 2010;126:e779-87.

22. Kumral A, Tuzun F, Yesilirmak DC, Duman N, Ozkan H. Genetic basis of apnoea of prematurity and caffeine treatment response: role of adenosine receptor polymorphisms: genetic basis of apnoea of prematurity. Acta Paediatr. 2012;101: e299-303.

23. He X, Qiu JC, Lu KY, Guo HL, Li L, Jia WW, et al. Therapy for apnoea of prematurity: a retrospective study on effects of standard dose and genetic variability on clinical response to caffeine citrate in Chinese preterm infants. Adv Ther. 2021;38:607-26.

24. Dobson NR, Hunt CE. Caffeine: an evidence-based success story in VLBW pharmacotherapy. Pediatr Res. 2018;84:333-40. 
25. Henderson-Smart DJ, De Paoli AG. Methylxanthine treatment for apnoea in preterm infants. Cochrane Database Syst Rev. 2010;12:CD000140.

26. Henderson-Smart DJ, Steer PA. Caffeine versus theophylline for apnea in preterm infants. Cochrane Database Syst Rev. 2010;1: CD000273.

27. Mayer CA, Haxhiu MA, Martin RJ, Wilson CG. Adenosine A2A receptors mediate GABAergic inhibition of respiration in immature rats. J Appl Physiol. 2006;100:91-7.

28. Wilson CG, Martin RJ, Jaber M, Abu-Shaweesh J, Jafri A, Haxhiu MA, et al. Adenosine A2A receptors interact with GABAergic pathways to modulate respiration in neonatal piglets. Respir Physiol Neurobiol. 2004;141:201-11.

29. Aranda JV, Gorman W, Bergsteinsson H, Gunn T. Efficacy of caffeine in treatment of apnea in the low-birth-weight infant. J Pediatr. 1977;90:467-72.

30. Aranda JV, Turmen T. Methylxanthines in apnea of prematurity. Clin Perinatol. 1979;6:87-108.

31. Puia-Dumitrescu M, Smith PB, Zhao J, Soriano A, Payne EH, Harper B, et al. Dosing and safety of off-label use of caffeine citrate in premature infants. J Pediatr. 2019;211:27-32.e1.

32. Brattström P, Russo C, Ley D, Bruschettini M. High-versus lowdose caffeine in preterm infants: a systematic review and metaanalysis. Acta Paediatr. 2019;108:401-10.

33. Ravichandran S, Chouthai NS, Patel B, Sharma A, Gupte A, Ma $\mathrm{MM}$, et al. Higher daily doses of caffeine lowered the incidence of moderate to severe neurodevelopmental disabilities in very low birth weight infants. Acta Paediatr. 2019;108:430-5.

34. McPherson C, Neil JJ, Tjoeng TH, Pineda R, Inder TE. A pilot randomized trial of high-dose caffeine therapy in preterm infants. Pediatr Res. 2015;78:198-204.

35. Schmidt B, Roberts RS, Davis P, Doyle LW, Barrington KJ, Ohlsson A, et al. Caffeine therapy for apnea of prematurity. $\mathrm{N}$ Engl J Med. 2006;354:2112-21.

36. Schmidt B, Roberts RS, Davis P, Doyle LW, Barrington KJ, Ohlsson A, et al. Long-term effects of caffeine therapy for apnea of prematurity. N Engl J Med. 2007;357:1893-902.

37. Schmidt B, Anderson PJ, Doyle LW, Dewey D, Grunau RE, Asztalos EV, et al. Survival without disability to age 5 years after neonatal caffeine therapy for apnea of prematurity. JAMA. 2012;307:275-82.

38. Gounaris AK, Grivea IN, Baltogianni M, Gounari E, Antonogeorgos G, Kokori F, et al. Caffeine and gastric emptying time in very preterm neonates. J Clin Med. 2020;9:1676.

39. Ilhan O, Bor M. Effects of caffeine on splanchnic oxygenation in preterm infants. Am J Perinatol. 2020. Epub ahead of print.

40. Welsh C, Pan J, Belik J. Caffeine impairs gastrointestinal function in newborn rats. Pediatr Res. 2015;78:24-8.

41. Gillot I, Gouyon JB, Guignard JP. Renal effects of caffeine in preterm infants. Biol Neonate. 1990;58:133-6.

42. Harer MW, Askenazi DJ, Boohaker LJ, Carmody JB, Griffin RL, Guillet $\mathrm{R}$, et al. Association between early caffeine citrate administration and risk of acute kidney injury in preterm neonates: results from the AWAKEN Study. JAMA Pediatr. 2018;172:e180322.

43. Ergenekon E, Dalgiç N, Aksoy E, Koç E, Atalay Y. Caffeine intoxication in a premature neonate. Paediatr Anaesth. 2001; 11:737-9.

44. Nakaoka S, Kawasaki Y, Inomata S, Makimoto M, Yoshida T. Caffeine toxicity in a preterm neonate. Pediatr Neonatol. 2017; 58:380-1.

45. Charles BG, Townsend SR, Steer PA, Flenady VJ, Gray PH, Shearman A. Caffeine citrate treatment for extremely premature infants with apnea: population pharmacokinetics, absolute bioavailability, and implications for therapeutic drug monitoring. Ther Drug Monit. 2008;30:709-16.
46. Henderson-Smart DJ, Davis PG. Prophylactic methylxanthines for endotracheal extubation in preterm infants. Cochrane Database Syst Rev. 2010;12:CD000139.

47. Doyle LW, Ranganathan S, Cheong JLY. Neonatal caffeine treatment and respiratory function at 11 years in children under 1,251 g at birth. Am J Respir Crit Care Med. 2017;196:1318-24.

48. Davis PG, Schmidt B, Roberts RS, Doyle LW, Asztalos E, Haslam R, et al. Caffeine for apnea of prematurity trial: benefits may vary in subgroups. J Pediatr. 2010;156:382-7.

49. Nylander Vujovic S, Nava C, Johansson M, Bruschettini M. Confounding biases in studies on early- versus late-caffeine in preterm infants: a systematic review. Pediatr Res. 2020;88: 357-64.

50. Amaro CM, Bello JA, Jain D, Ramnath A, D’Ugard C, Vanbuskirk S, et al. Early caffeine and weaning from mechanical ventilation in preterm infants: a randomized, placebo-controlled trial. J Pediatr. 2018;196:52-7.

51. Abu Jawdeh EG, O'Riordan M, Limrungsikul A, Bandyopadhyay A, Argus BM, Nakad PE, et al. Methylxanthine use for apnea of prematurity among an international cohort of neonatologists. J Neonatal Perinatal Med. 2013;6:251-6.

52. Eichenwald EC, Committee on Fetus and Newborn AAP. Apnea of prematurity. Pediatrics. 2016;137:e20153757.

53. Chung J, Tran Lopez K, Amendolia B, Bhat V, Nakhla T, SlaterMyer L, et al. Stopping caffeine in premature neonates: how long does it take for the level of caffeine to fall below the therapeutic range? J Matern Fetal Neonatal Med. 2020;1-5: Epub ahead of print.

54. Doyle J, Davidson D, Katz S, Varela M, Demeglio D, DeCristofaro J. Apnea of prematurity and caffeine pharmacokinetics: potential impact on hospital discharge. J Perinatol. 2016;36:141-4.

55. Miller MJ, Carlo WA, Martin RJ. Continuous positive airway pressure selectively reduces obstructive apnea in preterm infants. J Pediatr. 1985;106:91-4.

56. Sreenan C, Lemke RP, Hudson-Mason A, Osiovich H. Highflow nasal cannulae in the management of apnea of prematurity: a comparison with conventional nasal continuous positive airway pressure. Pediatrics. 2001;107:1081-3.

57. Al-Alaiyan S, Dawoud M, Al-Hazzani F. Positive distending pressure produced by heated, humidified high flow nasal cannula as compared to nasal continuous positive airway pressure in premature infants. J Neonatal Perinatal Med. 2014;7:119-24.

58. Lemyre B, Davis PG, de Paoli AG. Nasal intermittent positive pressure ventilation (NIPPV) versus nasal continuous positive airway pressure (NCPAP) for apnea of prematurity. Cochrane Database Syst Rev. 2002;1:CD002272.

59. Pantalitschka T, Sievers J, Urschitz MS, Herberts T, Reher C, Poets CF. Randomised crossover trial of four nasal respiratory support systems for apnoea of prematurity in very low birthweight infants. Arch Dis Child Fetal Neonatal Ed. 2009;94: F245-8.

60. Gizzi C, Montecchia F, Panetta V, Castellano C, Mariani C, Campelli M, et al. Is synchronised NIPPV more effective than NIPPV and NCPAP in treating apnoea of prematurity (AOP)? A randomised cross-over trial. Arch Dis Child Fetal Neonatal Ed. 2015;100:F17-23.

61. Tabacaru CR, Moores RR, Khoury J, Rozycki HJ. NAVAsynchronized compared to nonsynchronized noninvasive ventilation for apnea, bradycardia, and desaturation events in VLBW infants. Pediatr Pulmonol. 2019;54:1742-6.

62. Firestone K, Horany BA, de Leon-Belden L, Stein H. Nasal continuous positive airway pressure versus noninvasive NAVA in preterm neonates with apnea of prematurity: a pilot study with a novel approach. J Perinatol. 2020;40:1211-5.

63. Quitadamo P, Giorgio V, Zenzeri L, Baldassarre M, Cresi F, Borrelli $\mathrm{O}$, et al. Apnea in preterm neonates: what's the role of 
gastroesophageal reflux? A systematic review. Dig Liver Dis. 2020;52:723-9.

64. Zagol K, Lake DE, Vergales B, Moorman ME, Paget-Brown A, Lee $\mathrm{H}$, et al. Anemia, apnea of prematurity, and blood transfusions. J Pediatr. 2012;161:417-21.e1.

65. Abu Jawdeh EG, Martin RJ, Dick TE, Walsh MC, Di, Fiore JM. The effect of red blood cell transfusion on intermittent hypoxemia in ELBW infants. J Perinatol. 2014;34:921-5.

66. Kovatis KZ, Di Fiore JM, Martin RJ, Abbasi S, Chaundhary AS, Hoover S, et al. Effect of blood transfusions on intermittent hypoxic episodes in a prospective study of very low birth weight infants. J Pediatr. 2020;222:65-70.

67. Kirpalani H, Whyte RK. What is new about transfusions for preterm infants? An update. Neonatology. 2019;115:406-10.

68. Eichenwald EC, Aina A, Stark AR. Apnea frequently persists beyond term gestation in infants delivered at 24 to 28 weeks. Pediatrics. 1997;100:354-9.

69. Rhein LM, Dobson NR, Darnall RA, Corwin MJ, Heeren TC, Poets $\mathrm{CF}$, et al. Effects of caffeine on intermittent hypoxia in infants born prematurely: a randomized clinical trial. JAMA Pediatr. 2014;168:250-7.

70. Dobson NR, Rhein LM, Darnall RA, Corwin MJ, Heeren TC, Eichenwald E, et al. Caffeine decreases intermittent hypoxia in preterm infants nearing term-equivalent age. J Perinatol. 2017;37:1135-40.

71. Brockmann PE, Wiechers C, Pantalitschka T, Diebold J, Vagedes J, Poets CF. Under-recognition of alarms in a neonatal intensive care unit. Arch Dis Child Fetal Neonatal Ed. 2013;98: F524-7.

72. Ho T, Dukhovny D, Zupancic JA, Goldmann DA, Horbar JD, Pursley DM. Choosing wisely in newborn medicine: five opportunities to increase value. Pediatrics. 2015;136: e482-9.

73. Perfect Sychowski S, Dodd E, Thomas P, Peabody J, Clark R. Home apnea monitor use in preterm infants discharged from newborn intensive care units. J Pediatr. 2001;139:245-8.

74. Strehle EM, Gray WK, Gopisetti S, Richardson J, McGuire J, Malone S. Can home monitoring reduce mortality in infants at increased risk of sudden infant death syndrome? A systematic review. Acta Paediatr. 2012;101:8-13.

75. Raffay TM, Dylag AM, Sattar A, Abu Jawdeh EG, Cao S, Pax $\mathrm{BM}$, et al. Neonatal intermittent hypoxemia events are associated with diagnosis of bronchopulmonary dysplasia at 36 weeks postmenstrual age. Pediatr Res. 2019;85:318-23.

76. Fairchild KD, Nagraj VP, Sullivan BA, Moorman JR, Lake DE. Oxygen desaturations in the early neonatal period predict development of bronchopulmonary dysplasia. Pediatr Res. 2019;85:987-93.

77. Raffay TM, Martin RJ. Intermittent hypoxia and bronchial hyperreactivity. Semin Fetal Neonatal Med. 2020;25:101073.

78. Darnall RA, Chen X, Nemani KV, Sirieix CM, Gimi B, Knoblach S, et al. Early postnatal exposure to intermittent hypoxia in rodents is proinflammatory, impairs white matter integrity, and alters brain metabolism. Pediatr Res. 2017;82:164-72.

79. Poets CF, Roberts RS, Schmidt B, Whyte RK, Asztalos EV, Bader D, et al. Association between intermittent hypoxemia or bradycardia and late death or disability in extremely preterm infants. JAMA. 2015;314:595-603.

80. Gozal D. Sleep-disordered breathing and school performance in children. Pediatrics. 1998;102:616-20.

81. Hunt CE. Neurocognitive outcomes in sleep-disordered breathing. J Pediatr. 2004;145:430-2.

82. Janvier A, Khairy M, Kokkotis A, Cormier C, Messmer D, Barrington KJ. Apnea is associated with neurodevelopmental impairment in very low birth weight infants. J Perinatol. 2004; 24:763-8.
83. Greene MM, Patra K, Khan S, Karst JS, Nelson MN, Silvestri JM. Cardiorespiratory events in extremely low birth weight infants: neurodevelopmental outcome at 1 and 2 years. J Perinatol. 2014;34:562-5.

84. Pillekamp F, Hermann C, Keller T, von Gontard A, Kribs A, Roth B. Factors influencing apnea and bradycardia of prematurity - implications for neurodevelopment. Neonatology. 2007;91:155-61.

85. Tieder JS, Bonkowsky JL, Etzel RA, Franklin WH, Gremse DA, Herman B, et al. Brief resolved unexplained events (formerly apparent life-threatening events) and evaluation of lower-risk infants. Pediatrics. 2016;137:e20160590.

86. DeLaroche AM, Haddad R, Farooqi A, Sapién RE, Tieder JS. Outcome prediction of higher-risk brief resolved unexplained events. Hosp Pediatr. 2020;10:303-10.

87. Moon RY, Task Force on Sudden Infant Death Syndrome. SIDS and other sleep-related infant deaths: evidence base for 2016 updated recommendations for a safe infant sleeping environment. Pediatrics. 2016;138:e20162940.

88. Malloy MH. Prematurity and sudden infant death syndrome: United States 2005-2007. J Perinatol. 2013;33:470-5.

89. Di Fiore JM, MacFarlane PM, Martin RJ. Intermittent hypoxemia in preterm infants. Clin Perinatol. 2019;46:553-65.

90. Chen T, Hughes ME, Wang H, Wang G, Hong X, Liu L, et al. Prenatal, perinatal, and early childhood factors associated with childhood obstructive sleep apnea. J Pediatr. 2019;212:20-7.e10.

91. Thomas B, Thillainathan K, Delahunty M, Weichard A, Davey MJ, Nixon GM, et al. Cardiovascular autonomic control is altered in children born preterm with sleep disordered breathing. J Pediatr. 2019;206:83-90.

92. Tapia IE, Marcus CL, McDonough JM, Kim JY, Cornaglia MA, Xiao R, et al. Airway resistance in children with obstructive sleep apnea syndrome. Sleep. 2016;39:793-9.

93. Huang YS, Hsu JF, Paiva T, Chin WC, Chen IC, Guilleminault C. Sleep-disordered breathing, craniofacial development, and neurodevelopment in premature infants: a 2-year follow-up study. Sleep Med. 2019;60:20-5.

94. Hibbs AM, Johnson NL, Rosen CL, Kirchner HL, Martin R, Storfer-Isser A, et al. Prenatal and neonatal risk factors for sleep disordered breathing in school-aged children born preterm. J Pediatr. 2008;153:176-82.

95. Amin SB, Burnell E. Monitoring apnea of prematurity: validity of nursing documentation and bedside cardiorespiratory monitor. Am J Perinatol. 2013;30:643-8.

96. Mathew OP. Apnea of prematurity: pathogenesis and management strategies. J Perinatol. 2011;31:302-10.

97. Di Fiore JM, Poets CF, Gauda E, Martin RJ, MacFarlane P. Cardiorespiratory events in preterm infants: interventions and consequences. J Perinatol. 2016;36:251-8.

98. Kraaijenga JV, Hutten GJ, de Waal CG, de Jongh FH, Onland W, van Kaam AH. Classifying apnea of prematurity by transcutaneous electromyography of the diaphragm. Neonatology. 2018;113:140-5.

99. Williamson JR, Bliss DW, Paydarfar D. Forecasting respiratory collapse: theory and practice for averting life-threatening infant apneas. Respir Physiol Neurobiol. 2013;189:223-31.

100. Coughlin K, Posencheg M, Orfe L, Zachritz W, Meadow J, Yang $\mathrm{K}$, et al. Reducing variation in the management of apnea of prematurity in the intensive care nursery. Pediatrics. 2020;145: e20190861.

101. Alvaro RE, Khalil M, Qurashi M, Al-Saif S, Al-Matary A, Chiu A, et al. $\mathrm{CO}(2)$ inhalation as a treatment for apnea of prematurity: a randomized double-blind controlled trial. J Pediatr. 2012; 160:252-7.e1.

102. Joseph LJ, Goldberg S, Picard E. CO2 treatment for apnea. J Pediatr. 2009;154:627-8. author reply 8-9 
103. Ballout RA, Foster JP, Kahale LA, Badr L. Body positioning for spontaneously breathing preterm infants with apnoea. Cochrane Database Syst Rev. 2017;1:CD004951.

104. Gaugler C, Marlier L, Messer J. Sensory stimulations for the treatment of idiopathic apneas of prematurity. Arch Pediatr. 2007;14:485-9.

105. Cramer SJE, Dekker J, Dankelman J, Pauws SC, Hooper SB, Te, Pas AB. Effect of tactile stimulation on termination and prevention of apnea of prematurity: a systematic review. Front Pediatr. 2018;6:45.

106. Henderson-Smart DJ, Osborn DA. Kinesthetic stimulation for preventing apnea in preterm infants. Cochrane Database Syst Rev. 2002;2:CD000373.

107. Kesavan K, Frank P, Cordero DM, Benharash P, Harper RM. Neuromodulation of limb proprioceptive afferents decreases apnea of prematurity and accompanying intermittent hypoxia and bradycardia. PLoS ONE. 2016;11:e0157349.

108. Marlier L, Gaugler C, Messer J. Olfactory stimulation prevents apnea in premature newborns. Pediatrics. 2005;115:83-8.

109. Montealegre-Pomar A, Bohorquez A, Charpak N. Systematic review and meta-analysis suggest that Kangaroo position protects against apnoea of prematurity. Acta Paediatr. 2020;109: 1310-6.

110. Vliegenthart RJ, Ten Hove $\mathrm{CH}$, Onland W, van Kaam AH. Doxapram treatment for apnea of prematurity: a systematic review. Neonatology. 2017;111:162-71.

111. Terrin G, Passariello A, De Curtis M, Manguso F, Salvia G, Lega L, et al. Ranitidine is associated with infections, necrotizing enterocolitis, and fatal outcome in newborns. Pediatrics. 2012;129:e40-5.

112. Bairam A, Boukari R, Joseph V. Targeting progesterone receptors in newborn males and females: from the animal model to a new perspective for the treatment of apnea of prematurity? Respir Physiol Neurobiol. 2019;263:55-61.

113. Ren J, Ding X, Greer JJ. Ampakines enhance weak endogenous respiratory drive and alleviate apnea in perinatal rats. Am J Respir Crit Care Med. 2015;191:704-10.

114. Saroha V, Patel RM. Caffeine for preterm infants: fixed standard dose, adjustments for age or high dose? Semin Fetal Neonatal Med. 2020;25:101178.

115. Davis PG. When to start and stop caffeine and why respiratory status matters. Semin Fetal Neonatal Med. 2020;25:101175. 